\title{
8
}
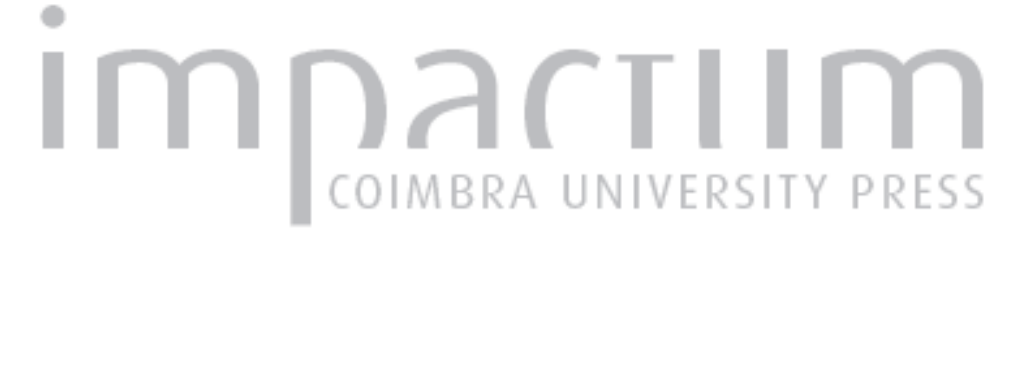

\section{Medidas de emergência para proteção do solo após incêndios florestais: resultados preliminares de algumas experiências na serra do Gerês}

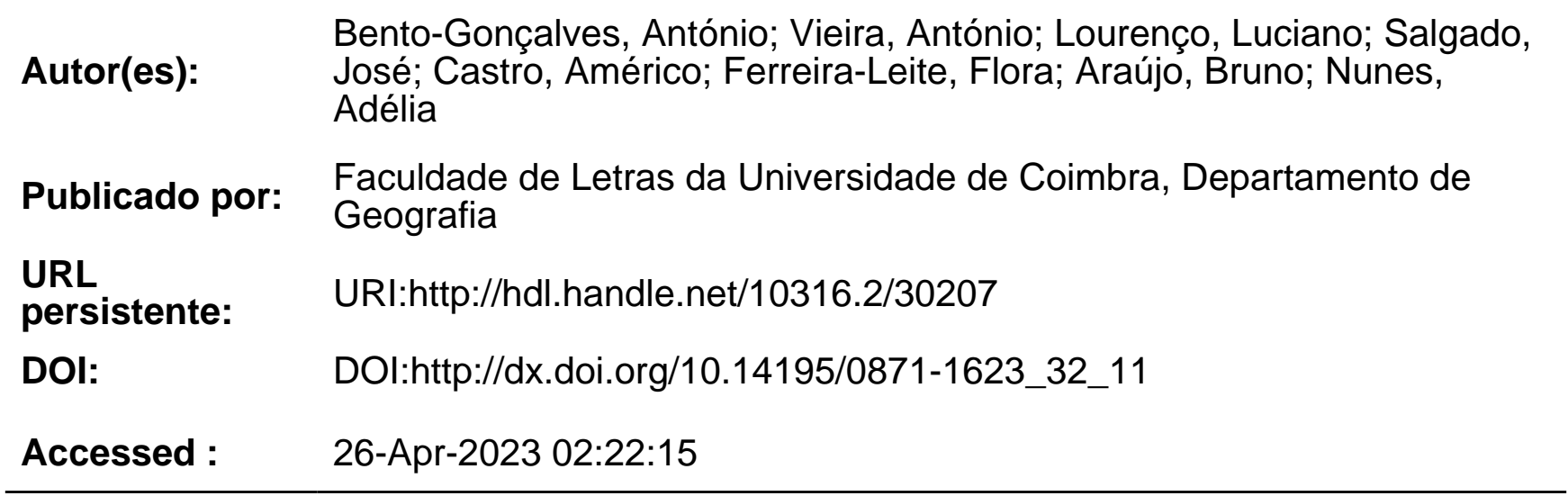

A navegação consulta e descarregamento dos títulos inseridos nas Bibliotecas Digitais UC Digitalis, UC Pombalina e UC Impactum, pressupõem a aceitação plena e sem reservas dos Termos e Condições de Uso destas Bibliotecas Digitais, disponíveis em https://digitalis.uc.pt/pt-pt/termos.

Conforme exposto nos referidos Termos e Condições de Uso, o descarregamento de títulos de acesso restrito requer uma licença válida de autorização devendo o utilizador aceder ao(s) documento(s) a partir de um endereço de IP da instituição detentora da supramencionada licença.

Ao utilizador é apenas permitido o descarregamento para uso pessoal, pelo que o emprego do(s) título(s) descarregado(s) para outro fim, designadamente comercial, carece de autorização do respetivo autor ou editor da obra.

Na medida em que todas as obras da UC Digitalis se encontram protegidas pelo Código do Direito de Autor e Direitos Conexos e demais legislação aplicável, toda a cópia, parcial ou total, deste documento, nos casos em que é legalmente admitida, deverá conter ou fazer-se acompanhar por este aviso. 


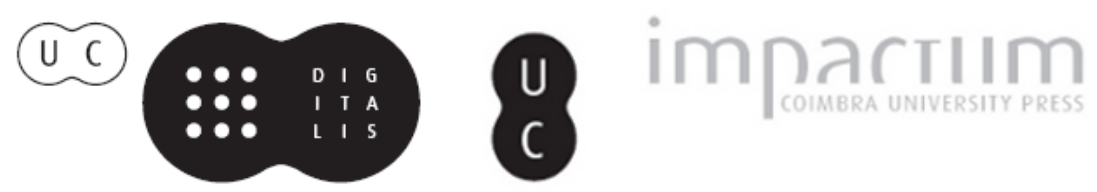

impactum.uc.pt digitalis.uc.pt 


\title{
Medidas de emergência para proteção do solo após incêndios florestais. Resultados preliminares de algumas experiências na serra do Gerês
}

\author{
António Bento-Gonçalves \\ Departamento de Geografia e Centro de Estudos em Geografia e Ordenamento do Território (CEGOT). Universidade do Minho. \\ bento@geografia.uminho.pt
}

\section{António Vieira}

Departamento de Geografia e Centro de Estudos em Geografia e Ordenamento do Território (CEGOT). Universidade do Minho. vieira@geografia.uminho.pt

\section{Luciano Lourenço}

Departamento de Geografia e Centro de Estudos em Geografia e Ordenamento do Território (CEGOT). Faculdade de Letras da Universidade de Coimbra. luciano@uc.pt

\section{José Salgado}

Aluno de mestrado. Departamento de Geografia. Universidade do Minho. josecastrosalgado@gmail.com

\section{Américo Castro}

Aluno de mestrado. Departamento de Geografia. Universidade do Minho. americocastro.am@hotmail.com

\section{Flora Ferreira-Leite}

Centro de Estudos em Geografia e Ordenamento do Território (CEGOT). Universidade do Minho. floraferreiraleite@gmail.com

\section{Bruno Araújo}

Aluno de mestrado. Departamento de Geografia. Universidade do Minho. bmmaraujo@gmail.com

\section{Adélia Nunes}

Departamento de Geografia e Centro de Estudos em Geografia e Ordenamento do Território (CEGOT). Faculdade de Letras da Universidade de Coimbra. adelia.nunes@fl.uc.pt

\section{Resumo:}

Uma das consequências dos incêndios florestais é o aumento da erosão da camada superior dos solos, onde se localizam, na maioria dos solos portugueses, os únicos nutrientes existentes. Num clima com características mediterrâneas, como é o caso do português, a máxima exportação dos sedimentos acontece, normalmente, nos primeiros 4 a 6 meses depois dos incêndios.

Assim, o projeto Soil Protec ${ }^{1}$ (Medidas de Emergência para Proteção de Solos após Incêndios Florestais) visa testar medidas de emergência, de baixo custo, a aplicar na proteção de solos, imediatamente após os incêndios florestais de baixa/média severidade, com base nas medições efetuadas em povoamentos de Pinus pinaster na serra do Gerês.

Palavras-chave: Incêndios florestais. Severidade. Erosão do solo. Medidas de emergência.

\section{Résumé:}

Mesures d'urgence pour protéger le sol après les incendies de forêt. Résultats préliminaires de quelques expériences dans la Serra do Gerês.

Une des conséquences des incendies de forêt est l'augmentation de l'érosion de la couche supérieure du sol, où ils sont situés, dans la plupart des sols portugaises, les seuls nutriments existants. Dans un climat de caractéristiques

\footnotetext{
${ }^{1}$ Financiado pelo CEGOT - Centro de Estudos em Geografia e Ordenamento do Território.
} 
méditerranéennes, telles que le portugais, l'exportation maximale des sédiments se produit normalement dans les 4-6 premiers mois après l'incendie.

L'objective du projet SoilProtec (Mesures d'urgence pour la protection des sols après les feux de forêt) est de tester des mesures d'urgence, à faible coût, pour être appliquées dans la protection des sols, immédiatement après les incendies de forêt, de de faible/moyenne gravité dans des peuplements de Pinus pinaster.

Mots-clés: Feux de forêt. Gravité. Erosion des sols. Mesures d'urgence.

\section{Abstract:}

Emergency measures to protect the soil after forest fires. Preliminary results of a research in the Serra do Gerês.

A consequence of the forest fires is the increasing erosion of the top soil, where the few existing nutrients of most of the Portuguese soils are located. In a climate of Mediterranean features, such as the Portuguese, the maximum sediment export occurs normally in the first 4-6 months after the fire.

The objective of the project SoilProtec (Emergency measures for soil protection after forest fires) is to test low cost emergency measures, to be applied in soil protection, immediately after forest fires of low/medium severity in stands of Pinus pinaster.

Key-words: Forest fire. Severity. Soil erosion. Emergency measures.

\section{Introdução}

Todos os anos, Portugal tem vindo a ser mais ou menos percorrido por incêndios florestais, com uma clara tendência positiva quer para o aumento anual do número de ocorrências e das áreas ardidas (Lourenço, 2011), quer para o acréscimo tanto do número e dimensão dos grandes incêndios (Ferreira-Leite, 2010) como, também, da sua recorrência (FerReira-Leite et al., 2011).

Como consequência aumenta a erosão da camada superior dos solos (Lourenço e Monteiro, 1989; Burch et al., 1989; Lourenço e Bento-Gonçalves, 1990; Imeson et al. 1992; Shakesby et al., 1993; Scott e Schulze, 1992; ScotT, 1993; ANDREU et al., 1994; LOURENÇO, 1996; InBAR et al., 1998; Coelho et al., 1995a, b; Coelho et al., 2004; Cerdà e Lasanta, 2005; Benavides-Solorio e MacDonald, 2005; BenTO-GonçALves et al., 2008), onde se localizam, na maioria dos solos portugueses, os únicos nutrientes existentes.

Num clima como o português, de características mediterrâneas, a exportação dos sedimentos e dos nutrientes, normalmente acontece nos primeiros 4 a 6 meses após os incêndios, pelo que é fundamental estudar e implementar um conjunto de soluções que reduzam essas perdas (Shakesby et al., 1993, Bento Gonçalves e Coelho, 1995; Shakesby et al., 1996, Walsh, 1998; Ruiz e Luque, 2010; Bento-Gonçalves e Lourenço, 2010; Vega et al., 2010).

No entanto, este processo está intimamente dependente de diversos aspetos, associados não só aos incêndios florestais, como sejam a sua recorrência, in- tensidade e severidade, ou a variabilidade espacial da hidrofobicidade do solo (Jungerius e DeJong 1989; Ritsema e DeKker, 1994; Coelho et al., 2004), mas também das características do local (altitude, declive, exposição, clima, litologia, ...), como o demonstraram os trabalhos pioneiros levados a efeito na serra da Lousã, situada na Região Centro, onde foram realizados os primeiros estudos em Portugal (Lourenço, 1989; Lourenço e Bento-GonÇALves, 1990; Lourenço, Bento-Gonçalves e Monteiro, 1991), pelo que cada estudo concreto se deverá adequar à realidade específica resultante do cruzamento de todos estes diferentes aspetos, o que implica o uso dos procedimentos adequados a cada uma dessas situações.

\section{Objetivos}

A maioria das medidas de proteção do solo após incêndios são relativamente dispendiosas e de difícil aplicabilidade, razão pela qual a maioria dos proprietários florestais não se mostra muitas vezes recetiva ao investimento nessas medidas, especialmente num contexto de baixo rendimento e de alto risco, que o investimento na floresta implica.

Assim, o projeto Soil Protec (Medidas de Emergência para Proteção de Solos após Incêndios Florestais) visa testar medidas de emergência, de baixo custo, a aplicar na proteção de solos, imediatamente após incêndios florestais de baixa/média severidade, com base em medições efetuadas em povoamentos de Pinus pinaster na serra do Gerês. 


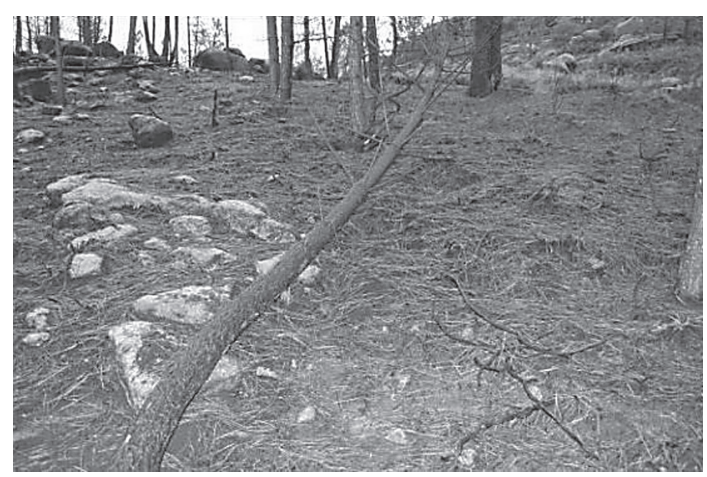

Fotografia 1

Pormenores da cobertura do solo com caruma, na área de estudo.

Neste sentido, pretende-se testar o papel da caruma, enquanto protetora do solo contra a erosão física (Fotografia 1), a qual tem a grande vantagem de existir no local do próprio incêndio, pois resulta, em parte, da queda de agulhas dos pinheiros queimados, após incêndios de baixa/média intensidade, comparativamente com o papel desempenhado pela palha, outro material frequentemente usado para cobrir os solos afetados por incêndios florestais (Ruiz e Luque, 2010).

\section{Os incêndios}

Os dois maiores incêndios florestais verificados nos últimos 15 anos, no concelho de Terras de Bouro, registaram-se em 2010 e, cada um deles, teve uma área ardida superior a 1 000ha (QuADRo I).

0 primeiro destes incêndios lavrou durante mais de 24 horas, em Vilarinho das Furnas, Campo do Gerês, com o alerta, dado por populares, pelas $15 \mathrm{~h} 48 \mathrm{~m}$ do dia 7 de Agosto. Foi extinto às $22 \mathrm{~h} 40 \mathrm{~m}$ do dia seguinte, totalizando uma área ardida de 2 316ha de mato. A causa deste incêndio, de acordo com as investigações, ficou a dever-se a negligência (causa 151 - fumadores a pé).

O segundo incêndio, identificado por populares às $13 \mathrm{~h} 15 \mathrm{~m}$ do dia 10 de Agosto, registou uma ardida de 1 184ha, menor do que a do anterior mas, ainda assim, considerada muito expressiva no contexto do concelho, foi causado por intencionalidade (causa 3 - causas estruturais).

Este incêndio deflagrou na Calcedónia, em Rio Caldo, aspeto que, apesar da menor dimensão do que a do acima referido, pode ser imprescindível para explicar o facto de ter lavrado durante 6 dias e ter apresentado uma proporção muito equilibrada entre a área ardida em povoamento e a área ardida em mato, 600 e $584 \mathrm{ha}$, respetivamente.
Quadro I

Área ardida (ha) e número de incêndios por classes de dimensão da área ardida (ha), no período de 1996 a 2010, no concelho de Terras de Bouro

\begin{tabular}{|c|c|c|c|c|c|c|}
\hline \multirow{2}{*}{ Ano } & \multirow{2}{*}{$\begin{array}{c}\text { Área ardida } \\
\text { (ha) }\end{array}$} & \multicolumn{5}{|c|}{$\begin{array}{c}\text { Número de incêndios florestais } \\
\text { por classes de dimensão de área ardida }\end{array}$} \\
\hline & & $<100$ ha & $\begin{array}{c}100- \\
500 \text { ha }\end{array}$ & $\begin{array}{c}500- \\
1000 \text { ha }\end{array}$ & $>1000 \mathrm{ha}$ & Total \\
\hline 1996 & 1143,87 & 105 & 2 & 1 & & 108 \\
\hline 1997 & 151,12 & 90 & & & & 90 \\
\hline 1998 & 197,21 & 119 & & & & 119 \\
\hline 1999 & 117,65 & 100 & & & & 100 \\
\hline 2000 & 552,78 & 121 & 2 & & & 123 \\
\hline 2001 & 648,87 & 198 & 1 & & & 199 \\
\hline 2002 & 229,81 & 136 & & & & 136 \\
\hline 2003 & 160,89 & 128 & & & & 128 \\
\hline 2004 & 175,75 & 136 & & & & 136 \\
\hline 2005 & 429,15 & 172 & & & & 172 \\
\hline 2006 & 747,44 & 127 & 3 & & & 130 \\
\hline 2007 & 864,75 & 129 & 2 & & & 131 \\
\hline 2008 & 220,73 & 36 & 1 & & & 37 \\
\hline 2009 & 1276,99 & 124 & & 1 & & 125 \\
\hline 2010 & 5403,07 & 59 & 2 & 2 & 2 & 65 \\
\hline Total & 12320,08 & 1780 & 13 & 4 & 2 & 1799 \\
\hline
\end{tabular}

Fonte: AFN

No entanto, este incêndio seguiu-se no tempo e no espaço a um outro, de mais reduzida dimensão (282ha), que apenas lavrou em mato e esteve ativo entre as $2 \mathrm{~h} 00$ do dia 8 de Agosto e as 10 h40 do dia 10 , do mesmo mês. Assim, do conjunto destes 2 incêndios resultou uma área ardida contínua de $1466 \mathrm{ha}$, a qual esteve sujeita a diferentes intensidades e severidades do fogo.

De forma a avaliarmos a severidade do incêndio da Calcedónia, no conjunto da área afetada, considerámos fundamental a exploração de imagens de satélite, recorrendo a ferramentas de deteção remota. Neste sentido, identificámos várias imagens obtidas pelos sensores dos satélites Landsat, anteriores e posteriores ao incêndio. A partir das imagens de 30 de Julho de 2010 e de 28 de Abril de 2011, provenientes do Landsat 5, procedemos ao cálculo da severidade, com base no algoritmo NBR (normalized burnt ratio), tendo-se criado cinco classes de representação dos resultados: severidade muito elevada, severidade elevada, severidade moderada, severidade reduzida e não ardida (Figura 1).

0 resultado obtido foi validado no campo, através de 9 pontos (Fotografia 2 e 3), onde foi avaliada a severidade do incêndio com base nas metodologias da BAER - Burned Area Emergency Response (PARsons et al., 2010) ${ }^{1}$ e LAMPIN et al. $(2003)^{2}$.

\footnotetext{
${ }^{1}$ Foram apenas tidos em conta dois fatores: tipo de vegetação (árvores, arbustos e ervas) e cobertura do solo.

${ }^{2}$ Foram tidos em linha de conta apenas os efeitos sobre os es paços naturais.
} 


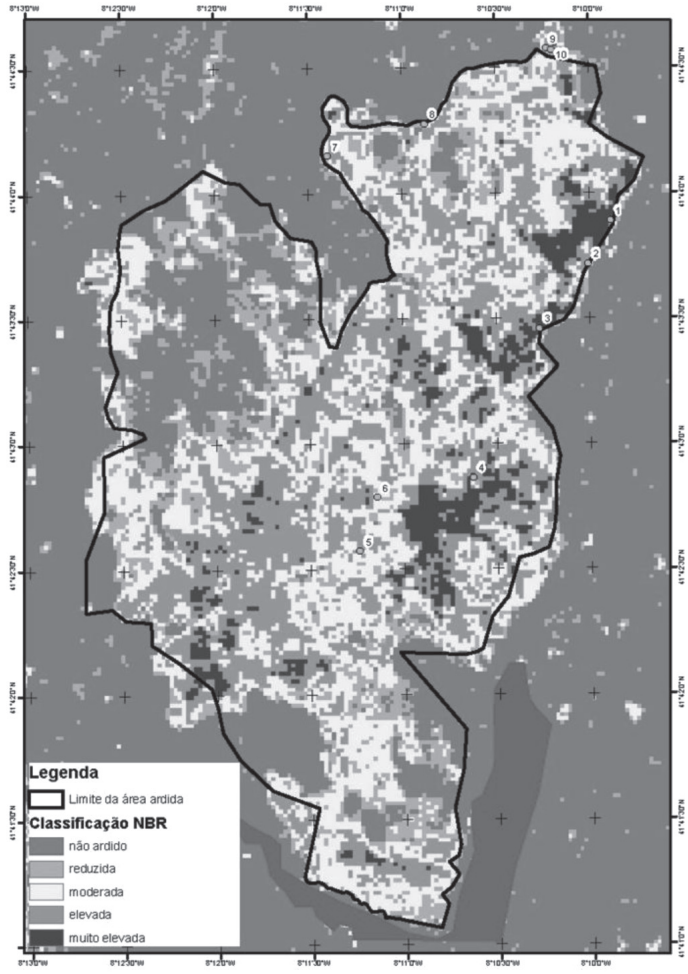

Figura 1

Mapa de severidade da área ardida total, correspondente aos incêndios de 7 e 10 de Agosto de 2010, no concelho de Terras de Bouro.

$\mathrm{Na}$ sequência dos dois grandes incêndios florestais (GIF) anteriormente mencionados e que afetaram uma área constituída, essencialmente, por granitos e por solos pedregosos e delgados (cambissolos), os quais, nos últimos 50 anos, estiveram sujeitos a uso florestal, com povoamentos de Pinus pinaster, e possuidora de um clima caracterizado por elevados quantitativos de precipitação, foram instaladas 6 parcelas ${ }^{3}$ experimentais, com 10 metros de comprimento por 2,5 m de largura ${ }^{4}$, numa área ardida considerada de média e alta severidade e com um declive médio de 15\%, (Fotografia 4 e Figura 2).

Cada uma destas parcelas foi cartografada com recurso a uma "estação total", o que permitiu ficar a conhecer o seu micro-relevo e, principalmente, acom-

${ }^{3}$ As parcelas utilizadas neste projeto foram adaptadas das parcelas usadas no Monte Cabalar (Galiza), no projeto "Protección de suelos forestales quemados mediante técnicas de rehabilitación: eficacia en el control de la erosión y efectos sobre la calidad del suelo", levado a cabo pelo "Instituto de Investigaciones Agrobiológicas de Galicia (CSIC)" e pelo "Centro de Investigación Forestal de Lourizán (Xunta de Galicia)".

${ }^{4}$ Obtivemos parcelas com uma área total de $25 \mathrm{~m}^{2}$, no entanto, tendo em conta que parte da superfície está ocupada pela tela (entre 38 e $42 \mathrm{~cm}$ em todo o seu perímetro), a área real de cada parcela é de aproximadamente $16 \mathrm{~m}^{2}$.

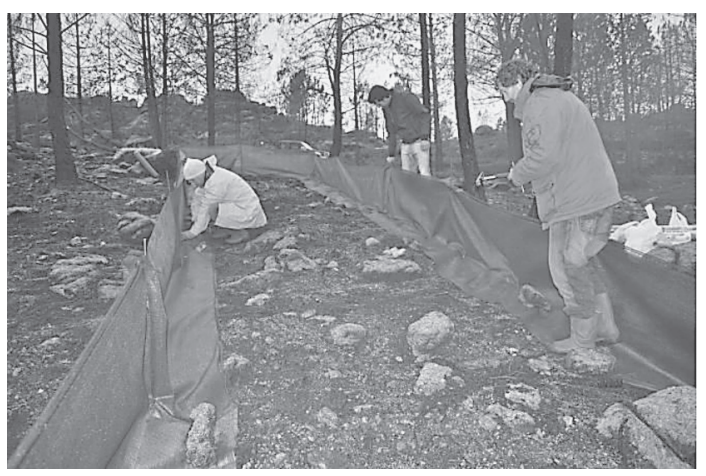

Fotografia 4

Pormenor da instalação de uma das parcelas experimentais.

panhar a sua evolução ao longo do período em estudo e em função da cobertura de cada uma das parcelas.

Para esse efeito, aplicou-se material seco, constituído por palha, em três das parcelas, e caruma, em duas das outras, tendo-se deixado uma delas sem qualquer tipo de cobertura, para controlo. As parcelas apresentavam, para o mesmo tipo de material, diferentes densidades de cobertura $\left(\mathrm{Kg} / \mathrm{m}^{2}\right)$, mas, em duas delas, era semelhante, quer se tratasse de palha, quer fosse caruma (QUADRo II, Figura 3 e Fotografia 5).

\section{QUADRO II}

Quantidade de palha e caruma (Kg/parcela, $\mathrm{Kg} / \mathrm{m}^{2}$ e Ton/ha) aplicadas nas parcelas experimentais.

\begin{tabular}{|l|l|l|l|l|l|l|}
\cline { 2 - 7 } \multicolumn{1}{c|}{} & \multicolumn{2}{c|}{ Kg/parcela } & \multicolumn{2}{c|}{ Kg/m ${ }^{2}$} & \multicolumn{2}{c|}{ Ton/ha } \\
\cline { 2 - 8 } \multicolumn{1}{c|}{} & Palha & Caruma & Palha & Caruma & Palha & Caruma \\
\hline Parcela 1 & & 8 & & 0,5 & & 5 \\
\hline Parcela 2 & 8 & & 0,5 & & 5 & \\
\hline Parcela 3 & 4 & & 0,25 & & 2,5 & \\
\hline Parcela 4 & 2 & & 0,125 & & 1,25 & \\
\hline Parcela 5 & \multicolumn{2}{|l|}{ Controlo } & & & \multicolumn{2}{c|}{ controlo } \\
\hline Parcela 6 & \multicolumn{2}{|c|}{4} & & 0,25 & & 2,5 \\
\hline
\end{tabular}

Para registo da precipitação, foram também insta-lados pluviómetros totalizadores, em número de dois.

Periodicamente procedeu-se à recolha dos materiais erosionados e que ficaram retidos em cada uma das parcelas e foi medida a precipitação nos dois pluviómetros.

Posteriormente, em laboratório, os materiais foram secos e, depois, pesados, para serem sujeitos à metodologia "loss on ignition", a fim de se determinarem as componentes orgânica e mineral de cada amostra, sendo a componente mineral posteriormente analisada em termos da sua granulometria.

${ }^{5} \mathrm{O}$ método de perda de peso por ignição (SCHulte et al., 1987) consiste na determinação gravimétrica do $\mathrm{CO}_{2}$ de uma amostra de solo submetida a alta temperatura de ignição. 


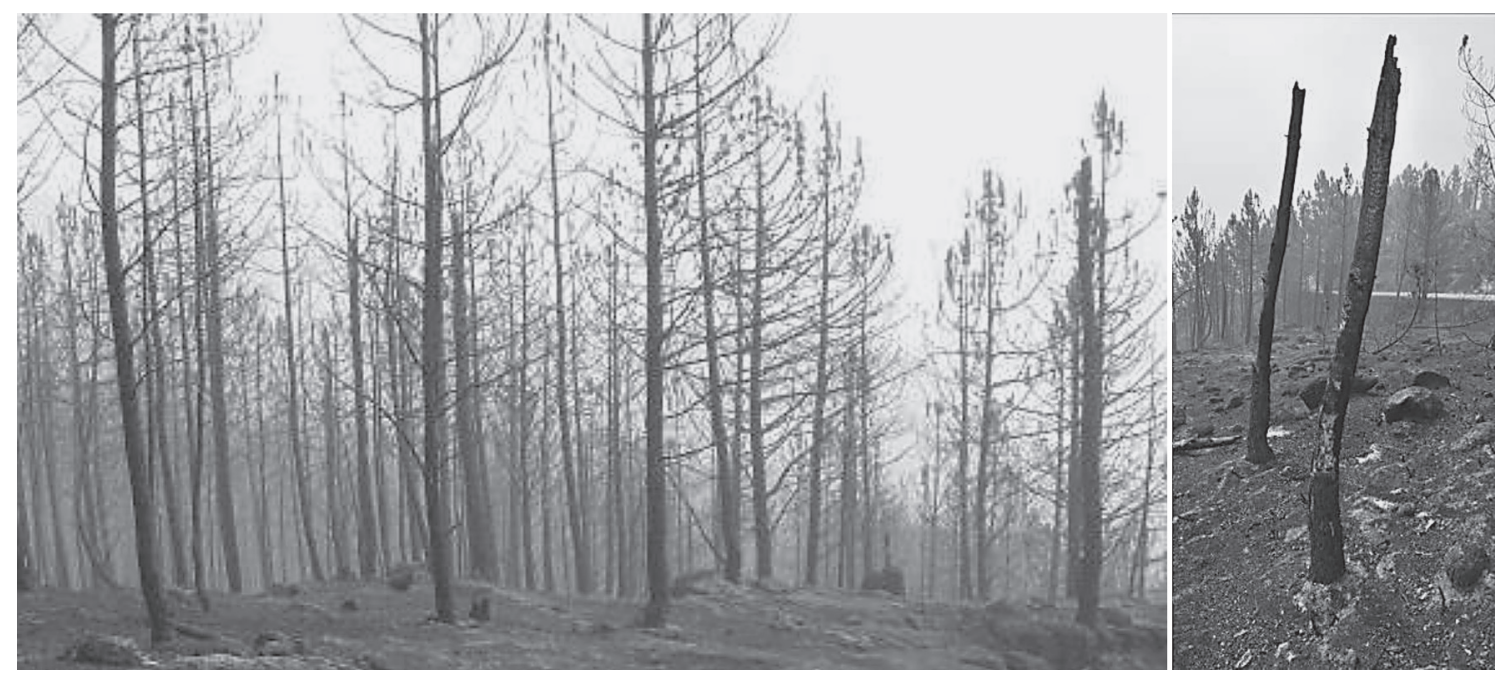

Fotografia 2 e 3

Junceda - Áreas ardidas com média severidade (à esquerda) e alta severidade (à direita).

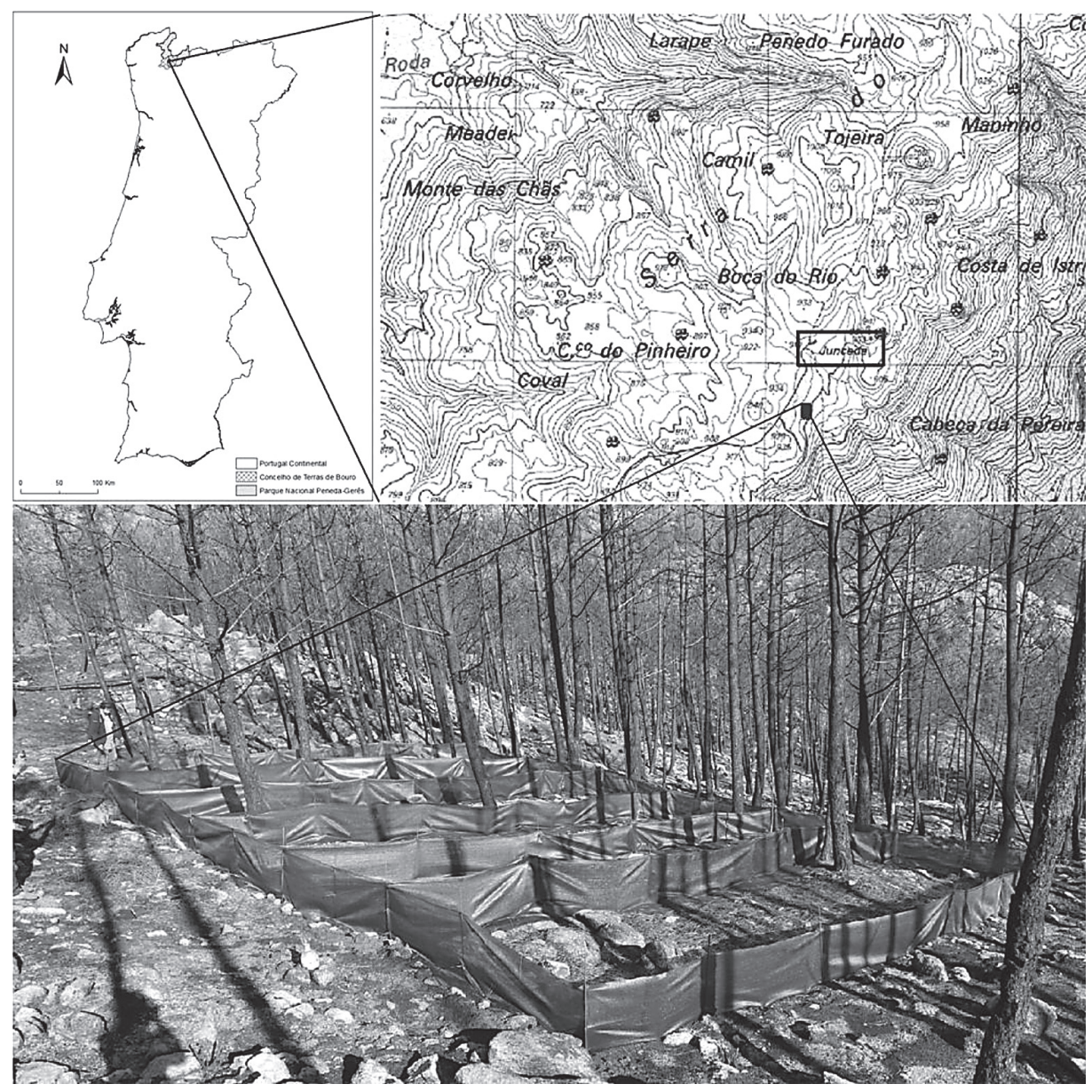

Figura 2

Localização da área de estudo (Junceda, Terras do Bouro). 


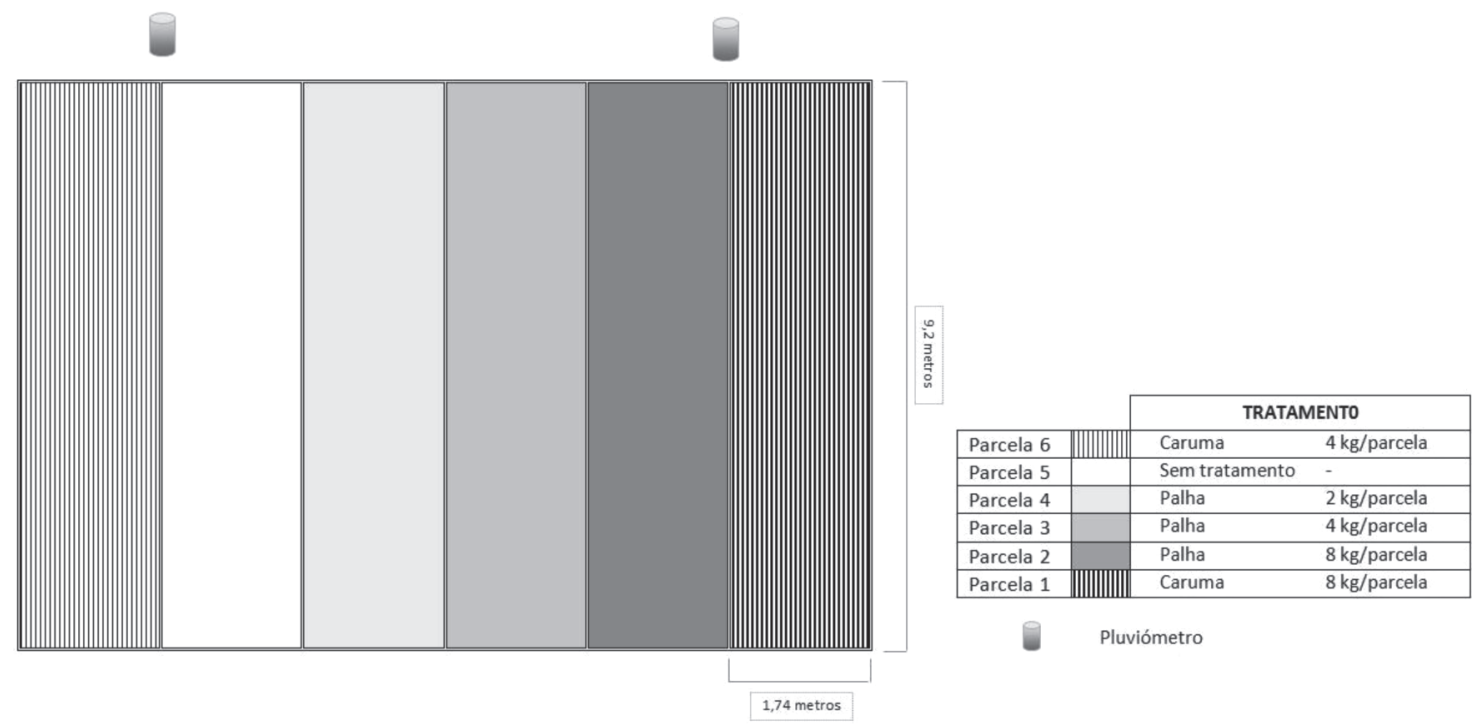

Figura 3

Desenho experimental das parcelas instaladas para testar medidas de emergência de proteção do solo após os incêndios.

\section{Resultados preliminares}

Numa análise superficial dos primeiros resultados, verificamos que as taxas anuais de erosão observadas nas parcelas (com e sem tratamento) não se mostraram significativas (Figura 4), podendo a erosão ser considerada como tolerável.

Com efeito, em condições semelhantes às verificadas na nossa área de estudo, Diaz-Fierros et al. (1982) considerou, para a Galiza, 3 limiares de risco de erosão, que correspondem respetivamente a 11, 30 e 100 Ton/ ha/ano. Deste modo, até 11 Ton/ha/ano a erosão considera-se tolerável, passando a ligeira, quando se situa entre 11 e 30 Ton/ha/ano, ou moderada, quando posicionada entre 30 e $100 \mathrm{Ton} / \mathrm{ha} / \mathrm{ano}$, e grave, quando superior a este último valor.

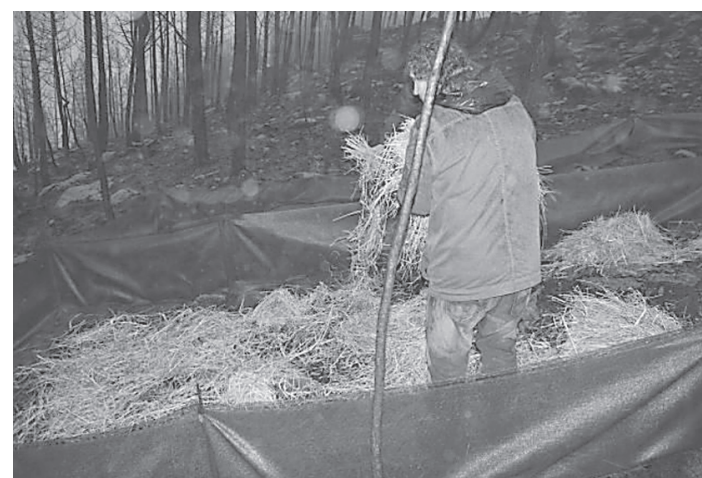

Fotografia 5

Detalhe da aplicação de palha numa das parcelas.
Também a FAO-PNUMA-UNESCO (1980) apresentam uma classificação onde existem 3 Graus de Perigo de degradação de solos, que correspondem respetivamente a 10, 50 e 200 Ton/ha/ano, onde, abaixo das 10 Ton/ha/ano o perigo de degradação de solos considerase muito baixo ou nulo, passando a baixo entre as $10 \mathrm{e}$ as 50 Ton/ha/ano, moderado entre as 50 e as 200 Ton/ ha/ano e alto acima das 200 Ton/ha/ano.

A única exceção ao facto da erosão poder ser considerada tolerável foi a parcela 4 , sujeita a um tratamento com 1,25 toneladas de palha por hectare, a qual ultrapassou largamente as 10-11 Ton/ha/ano, com mais de $21 \mathrm{Ton} / \mathrm{ha} / \mathrm{ano}$. Todavia, boa parte deste resultado ficou a dever-se à receção sistemática de material proveniente da parcela 5 (parcela de controlo), devido à impossibilidade do total isolamento do tipo de parcelas usadas neste projeto.

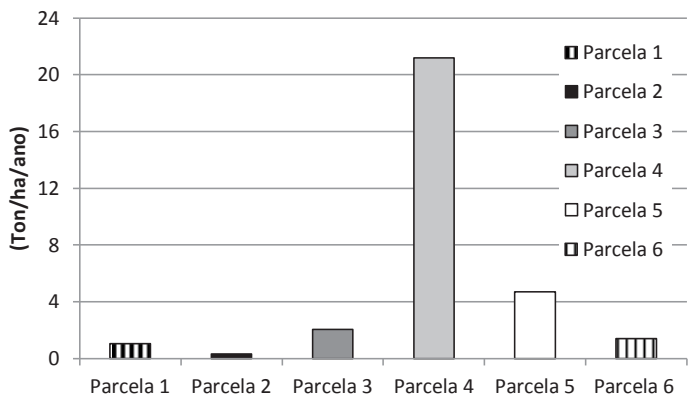

Figura 4

Taxas de erosão (Ton/ha/ano). 


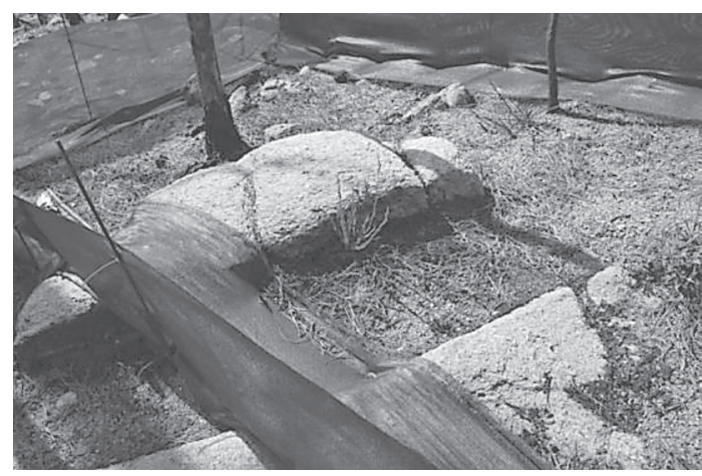

\section{Fotografia 6}

Aspeto de pormenor do terreno pedregoso, numa das parcelas experimentais.

Assim, um dos primeiros resultados obtidos foi a verificação da pouca adequabilidade deste tipo de parcelas a vertentes com solos delgados e com relevo pouco uniforme e muito pedregosos (Fotografia 6), dado que, muitas vezes, a influência do microrelevo, com a existência de pequenas "piscinas de sedimentos" a promoverem a retenção de elevadas quantidades de sedimentos (Fotografia 7), parece sobrepor-se à influência dos tratamentos efetuados.

A segunda conclusão, que se pode extrair da análise dos primeiros resultados, aponta claramente no sentido de uma grande eficácia da proteção concedida por qualquer um dos tipos de cobertura usados (palha ou caruma), durante cerca de um ano, período após o qual, com a progressiva redução da cobertura (da palha e da caruma), essa eficácia parece diminuir (Figura 5).

Com efeito, apesar do primeiro grande pico de erosão se ter registado entre 18 de dezembro de 2010 e 15 de janeiro de 2011, por ter correspondido a um período de elevada precipitação $(612,33 \mathrm{~mm})$, o maior

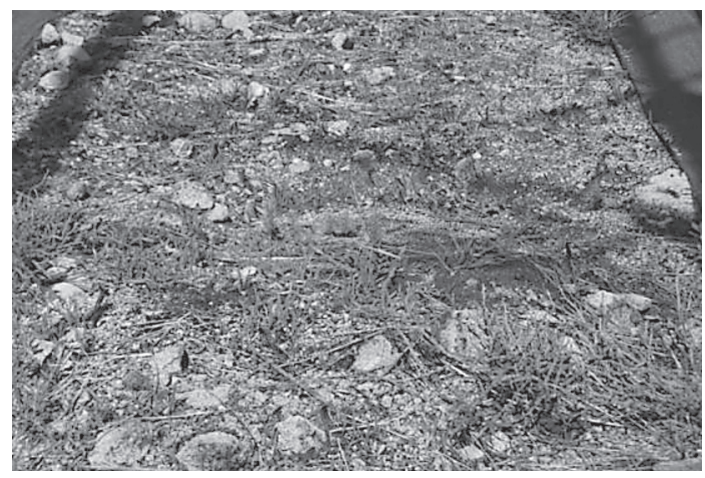

Fotografia 7

Pormenor de uma "piscina de sedimentos" existente no interior de uma das parcelas. pico erosivo só veio a ocorrer nove meses depois, entre 14 de Setembro e 28 de Outubro de 2011 (Figura 5), quando, apesar deste período só ter registado cerca de metade da precipitação $(290,75 \mathrm{~mm})$ verificada no $2^{\circ}$ período e de nas parcelas já existir menos material disponível para ser mobilizado. Contudo, neste mês, a cobertura das parcelas, quer de palha quer de caruma, já se encontrava bastante degradada, o que terá favorecido o transporte do material. Por outro lado, em contrapartida, a reduzida precipitação dos meses anteriores terá desfavorecido esse transporte, permitindo alguma acumulação de material. Deste modo, com material disponível e na diminuição da sua retenção, por degradação da cobertura, é natural que na presença de maior abundância de chuva e, porventura de maior intensidade da precipitação, a quantidade de material transportado tivesse sido a maior do período em estudo.

Comparando diretamente a eficácia de cada um dos materiais em função da quantidade de material aplicada, verificamos que, para o caso dos $0,5 \mathrm{Kg} / \mathrm{m}^{2}$ ( 5 Ton/ha), a palha, exceto em situações muito pontuais, revela-se mais eficaz que a caruma, parecendo ainda ser mais durável (Figura 6).

No que respeita à cobertura de $0,25 \mathrm{Kg} / \mathrm{m}^{2}(2,5$ Ton/ha) a situação parece inverter-se, pois a caruma, no primeiro ano, confere maior proteção ao solo, registando sistematicamente taxas de erosão inferiores às da parcela protegida por igual quantidade de palha. No entanto, depois do primeiro ano, a situação, aparentemente, inverte-se, passando a palha a ser mais eficaz na proteção do solo (Figura 7).

Assim, os primeiros resultados, para além de revelarem uma maior durabilidade da proteção conferida pela palha relativamente à caruma, apontam para uma maior eficácia, no primeiro ano, da palha para densidades de cobertura de 5 Ton/ha e de maior eficácia da caruma para densidades de cobertura de 2,5 Ton/ha.

Como ainda nos encontramos numa fase de trabalho laboratorial e de tratamento da informação recolhida, de momento não é possível acrescentar muito mais em termos de resultados, pois tal só será possível obter após a conclusão da análise mais pormenorizada dos dados, a qual nos irá permitir uma melhor interpretação da realidade.

\section{Nota final}

O objetivo final do projeto SoilProtec é o de recomendar, àqueles que detêm responsabilidades na ges- 


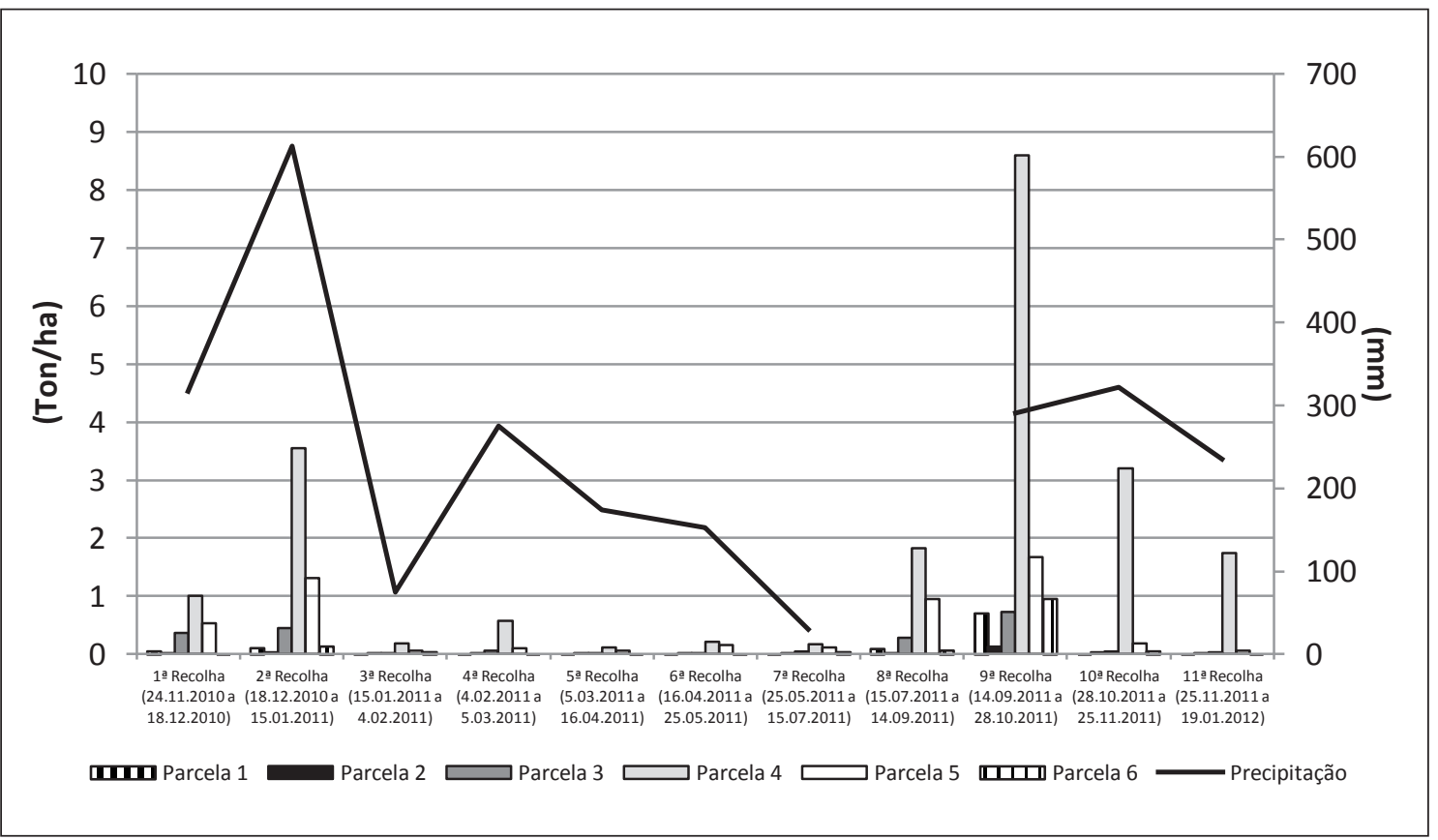

Figura 5

Evolução das taxas de erosão (Ton/ha) em cada parcela e da precipitação (mm), entre dezembro de 2010 e Janeiro de 2012.

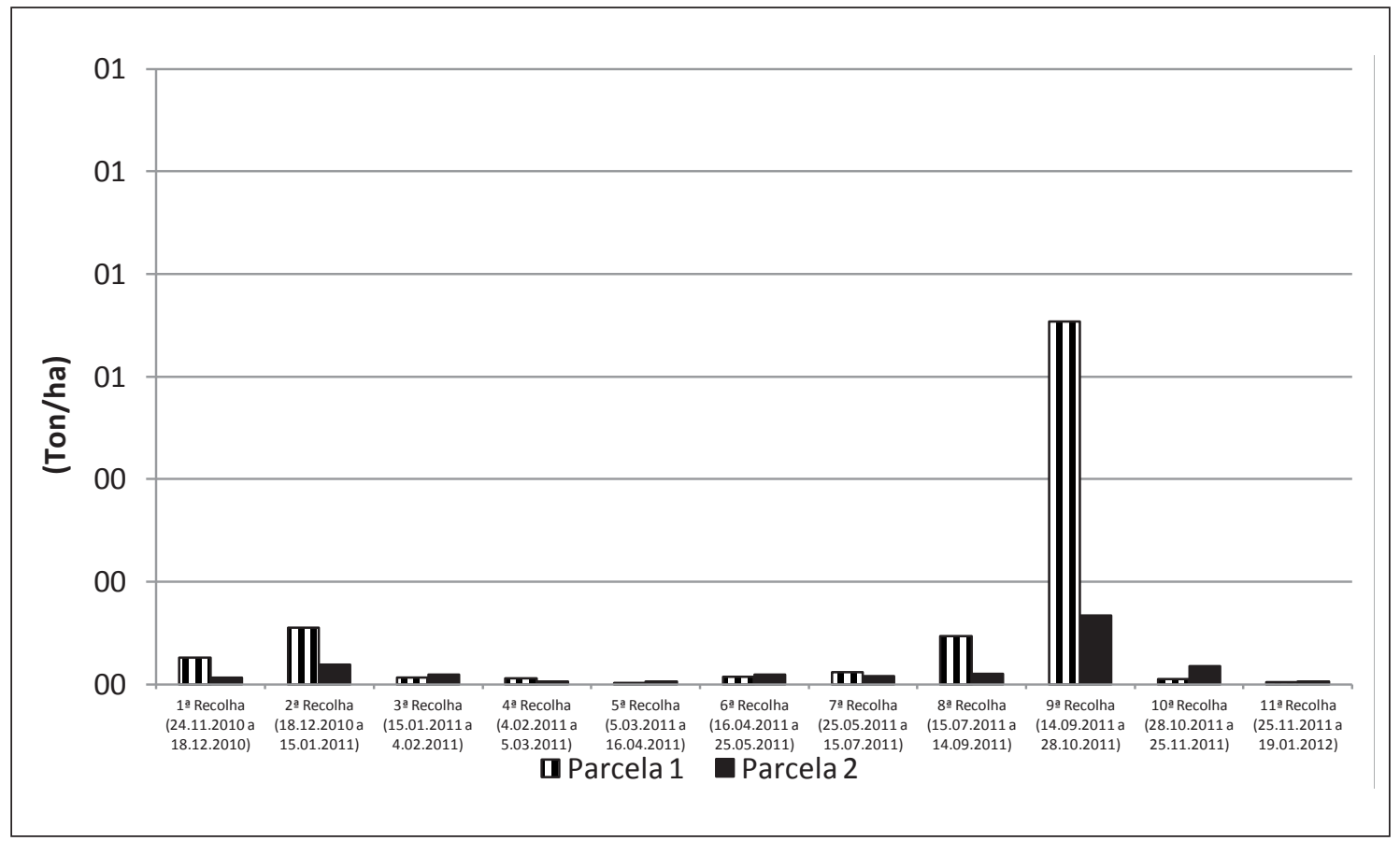

Figura 6

Evolução comparativa das taxas de erosão (Ton/ha) nas parcelas sujeitas a tratamentos com densidades de cobertura de $0,5 \mathrm{Kg} / \mathrm{m}^{2}$ ( 5 Ton/ha) de caruma e palha, entre dezembro de 2010 e Janeiro de 2012. 


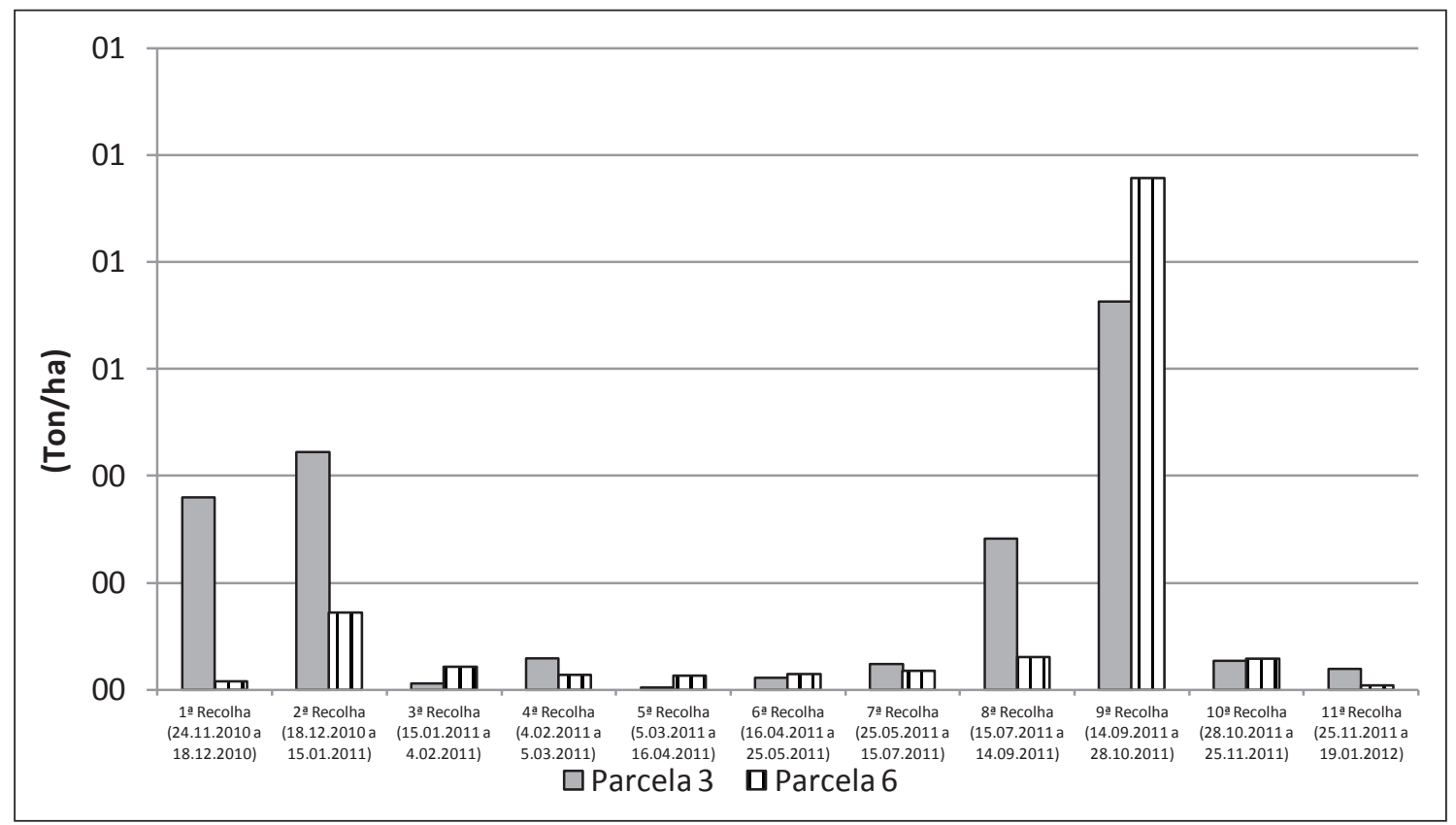

Figura 7

Evolução comparativa das taxas de erosão (Ton/ha) nas parcelas sujeitas a tratamentos com densidades de cobertura de $0,25 \mathrm{Kg} / \mathrm{m}^{2}(2,5 \mathrm{Ton} / \mathrm{ha})$ de caruma e palha, entre dezembro de 2010 e Janeiro de 2012.

tão de áreas queimadas, um tratamento expedito que, depois de identificadas as áreas críticas onde devem ser feitas intervenções, permita obter os melhores resultados de conservação do solo com o menor preço possível e sem introdução de elementos externos ao ambiente florestal de montanha, o que, por conseguinte, terá um impacte significativo sobre a conservação dos solos, a vegetação a recuperar e, portanto, sobre todo o funcionamento do ecossistema.

Os primeiros resultados apontam para a eficácia de ambas as medidas de proteção testadas (palha e caruma), sobretudo durante o primeiro ano após o incêndio florestal, parecendo indicar que a proteção começa a ser menos eficaz no segundo ano. Embora estejamos apenas a lidar com resultados provisórios, parece haver uma maior proteção da palha, relativamente à caruma, quando aplicada em maior quantidade, embora, no entanto, a proteção da caruma, neste primeiro ano, tenha sido também muito eficaz, quando aplicada em menor quantidade.

Todavia, se tivermos em consideração que a patha é um elemento exógeno ao ecossistema florestal e que ela transporta sementes que podem alterar a sua composição florística, a caruma talvez seja a opção preferível, até porque pode existir no local, evitandose, assim, o transporte de longas distâncias.

A acrescer a esta realidade, a palha apresenta maior custo, tendo em conta que tem de ser comprada a valores que rodam os $4 € /$ fardo de $20 \mathrm{Kg}^{6}$, implicando ainda, tal como a caruma, o seu transporte até ao local e posterior aplicação no terreno.

Atendendo a estes valores, para um tratamento com $0,25 \mathrm{~kg} / \mathrm{m}^{2}$ (2,5 Ton $\left./ \mathrm{ha}\right)$, um fardo de palha (20Kg) permitiria cobrir uma área de $80 \mathrm{~m}^{2}$, o que corresponde a um custo de aproximadamente 5 cêntimos por metro quadrado, ou seja $500 € /$ ha (mais o transporte e a mão de obra).

Assim, embora a caruma nos pareça ser a melhor opção, a sua utilização terá que ser revestida de alguns cuidados, pois não nos podemos esquecer de que se deslocarmos grande quantidades de caruma de uma área não afetada por um incêndio para outra que foi percorrida pelo fogo, corremos o risco de alterar e desproteger a área fornecedora. Assim, ao retirarmos a caruma deste espaço, vamos reduzir a camada protetora e a matéria orgânica destes solos, podendo ainda a técnica de recolha implicar alguma mobilização superficial do solo, correndo-se assim o risco de o empobrecer e de o expor aos agentes erosivos.

Assim, caso se opte por esta solução, terá sempre que se ter o cuidado de não tirar a totalidade da caruma, removendo apenas a parte superior, não desprotegendo e tentando não mobilizar a camada super-

\footnotetext{
${ }^{6}$ Valor em Novembro de 2010 por fardo de $20 \mathrm{Kg}$.
} 
ficial do solo, evitando ainda recolher a caruma em áreas declivosas.

Contudo, este artigo, pelas razões apontadas, apenas visa dar a conhecer o desenho experimental e alguns aspetos metodológicos do projeto SoilProtec, esperando-se para breve a publicação dos primeiros resultados consolidados sobre a perda de solo e a eficácia de cada um dos tratamentos utilizados na proteção de emergência do solo após incêndios.

\section{Agradecimentos}

Os autores querem aqui manifestar o seu agradecimento ao Parque Nacional Peneda Gerês, especialmente ao Seu Diretor, Dr. Lagido Domingos e à Eng $^{\mathrm{a}}$. Maria do Carmo Oliveira, pela colaboração prestada neste projeto, bem como ao Dr. Chris Chaffer pela sua colaboração na elaboração da cartografia de severidade.

\section{Bibliografia}

Andreu, V.; Forteza, J.; Rubio, J. L. e Cerni, R. (1994) - "Nutrient losses in relation to vegetation cover on automated field plots”. In Rickson, R. J. (Ed.) Conserving Soil Resources. Cambridge Univ. Press, pp. 116-126.

Benavides-Solorio, J. e MacDonald, L. H. (2005) - "Measurement and prediction of post-fire erosion at the hillslope scale, Colorado Front Range". International Journal of Wildland Fire, 14, pp. 457-474.

Bento-Gonçalves, A. J. e Coelho, C. (1995) - "Wildfire impacts on soil loss and runoff in dry mediterranean forest, Tejo basin, Portugal: preliminary results". Proceedings of Course on Desertification in a European Context. Physical and Socio-Economic Aspects, Bruxelles, pp. 361-369.

Bento-Gonçalves, A. J.; Vieira, A.; Ferreira, A. e Coelho, C. (2008) - "Caracterização geomorfológica e implementação de um sistema integrado de informação, em ambiente SIG, no âmbito do projeto RECOVER (Estratégias de remediação de solos imediatamente após incêndios florestais)". Revista Geografia Ensino \& Pesquisa, 12, 1, Santa Maria, Rio Grande do Sul, Brasil, pp. 3721-3735.

Bento-Gonçalves, A. J. e Lourenço, L. (2010) - "The study and measurement of overland flow and soil erosion on slopes affected by forest fires in Lousã mountain - main results". Actas das Jornadas Internacionales Investigación y gestión para la proteccion del suelo y restauración de los ecossistemas forestales affectados por incêndios forestales, Santiago de Compostela, pp. 107-110.

Burch, G. J.; Moore, I. D. e Burns, J. (1989) - "Soil hydrophobic effects on infiltration and catchment runoff". Hydrological Processes, 3, pp. 211-222.

Cerdì, A. e Lasanta, T. (2005) - "Long-term erosional responses after fire in the Central Spanish Pyrenees". Catena, 60, pp. 59-80.

Coelho, C.; Shakesby, R. e Walsh, R. (1995a) - "Effects of forest fires and post-fire land management practice on soil erosion and stream dynamics, Águeda basin, Portugal". Soil and groundwater research report $V$, European Commission.

Coelho, C.; Shakesby, R.; González, M.; Ternan, L.; Walsh, R. e Williams, A. G. (1995b) - "IBERLIM: Land management and erosion limitation in the Iberian Peninsula". Final Report to the EC in fulfilment of Project EV5V-0041 Land management practice and erosion limitation in contrasting wildfire and gullied locations in the Iberian Peninsula (unpublished).

Coelho, C.; Ferreira, A.; Boulet, A. e Keizer, J. (2004) - "Overland flow generation processes, erosion yields and solute loss following different intensity fires". Quarterly Journal of Engineering Geology and Hydrogeology, 37, 3, pp. 233-240.

Diaz-Fierros, V.; Gill Sotres, F.; Cabaneiro, A.; Arballas, T.; Leiros de la Peña, M. C. e Villar Celorio, M. C. (1982) - "Efectos erosivos de los incêndios forestales en suelos de Galicia". Anales de Edafología y Agrob. XLI, 3-4, pp. 627-639.

FAO-PNUMA-UNESCO (1980) - Metodología provisional para la evaluación de la degradación de los suelos. Organización de las Naciones Unidas para el Desarrollo de la Agricultura y la Alimentación (FAO), Programa de las Naciones Unidas para el Medio Ambiente (PNUMA), Organización de las Naciones para el Medio Ambiente (UNESCO), Roma, FAO.

FerReIRA-LeITE, F. (2010) - Caracterização dendrocaustológica do Noroeste Português - o caso dos grandes incêndios florestais. Tese de Mestrado, Universidade do Minho, Gumarães.

Ferreira-Leite, F.; Bento-Gonçalves, A. e Vieira, A. (2011) - "The recurrence interval of forest fires in Cabeço da Vaca (Cabreira Mountain - Northwest of Portugal)". Environmental Research 111 pp. 215-221.

Imeson, A. C.; Verstraten, J. M.; Van Mullingen, E. J. e Sevink, J. (1992) - "The effects of fire and water repellency on infiltration and runoff under Mediterranean type forests". Catena 19, pp. 345-361.

Jungerius, P. D. e DEJong, J. H. (1989) - "Variability of water repellency in the dunes along the Dutch coast". Catena, 16, pp. 491-497. 
Lampin-Cabaret C.; Japplot, M.; Alibert, N. e Manlay, R. (2003) "Une échelle d'intensité pour le phénomène Incendie de forêts", SIRNAT - JPRN, Orléans.

LOURENÇO, L. (1989) "Erosion of agro-forester soil in mountains affected by fire in Central Portugal". Pirineos. A journal on mountain ecology, Jaca, 133, pp. 55-76.

Lourenço, L. e Bento-Gonçalves, A. (1990) - "The study and measurement of surface flow and soil erosion on slopes affected by forest fires in the Serra da Lousã". Proceedings, International Conference on Forest Fire Research, Coimbra, pp. C.05-1 a 13.

Lourenço, L.; Bento-Gonçalves, A. e MonteiRo, R. (1991) - "Avaliação da erosão dos solos produzida na sequência de incêndios florestais". Comunicações II Congresso Florestal Nacional, II, Porto, pp. 834-844.

Parsons, A.; Robichaud, P.; Lewis, S.; Napper, C. e Clark, J. (2010) Field guide for mapping post-fire soil burn severity. Gen. Tech. Rep. RMRS-GTR-243. Fort Collins, CO: U.S. Department of Agriculture, Forest Service, Rocky Mountain Research Station.

Ritsema, C. J. e DekKer, L. W. (1994) - "How water moves in a water-repellent sandy soil". Dynamics of fingered flow. Water Resources Research, 30, pp. 2519-2531.

Ruiz, J. e Luque, I. (2010) - "Actuaciones de emergencia para la defense del suelo tras un gran incendio forestall em Andalucia". Actas das Jornadas Internacionales - Investigación y gestión para la proteccion del suelo y restauración de los ecossistemas forestales affectados por incêndios forestales, Santiago de Compostela., pp. 49-64.

Scott, D. e Schulze, R. (1992) - "The hydrological effects of a wildfire in a eucalypt afforested catchment". S.A. Forestry Journal, 160, pp. 67-74.

ScorT, D. (1993) - "The hydrological effects of fire in South African mountain catchments". Journal of Hydrology, 150, pp. 409-432.
Shakesby, R.; Boakes, D., Coelho, C.; Bento-Gonçalves, A. e Walsh, R. (1993) - "Limiting the erosional effect of forest fires: background to the IBERLIM research programme in Águeda and Tejo basins, Portugal". Swansea Geographer, 30; Swansea, pp. 132 - 154.

Shakesby, R.; Boakes, D., Coelho, C.; Bento-Gonçalves, A. e Walsh, R. (1996) - "Limiting the soil degradation impacts of wildfire in pine and eucalyptus forests, Portugal: comparison of alternative post-fire management practices". Applied Geography, Vol. 16, 4, Elsevier Science Ltd, pp. 337-355.

Shakesby, R.; Ferreira, A.; Ferreira, C.; Stoof, C.; Urbanek, E. e WALSH, R. (2009) - "Wildfires in Portugal: characteristics, soil degradational impacts and mitigation measures". Desire. (http://www.slideshare.net/medesdesire/ wildfire-2009)

Schulte, E.; Peters, J. e Hodgson, P. (1987) - Wisconsin Procedures for soil testing, plant analysis and fud \& forage analysis. Madison: University of Wisconsin/Department of soil Science.

Vega, J.; Serradab, R.; Hernandoc, C.; Rincónd, A.; Ocañae, L.; Madrigalc, J.; Fontúrbela, M.; Pueyo, J.; Agullar, V.; Guijarroc, M.; Carrilllo, A.; Fernándeza, C. e Marinoc, E. (2010) - "Actuaciones técnicas post-incendio y severidad del fuego:Proyecto Rodenal". Actas das Jornadas Internacionales - Investigación y gestión para la proteccion del suelo y restauración de los ecossistemas forestales affectados por incêndios forestales, Santiago de Compostela, pp. 305-308.

Walsh, R.; Coelho, C.; Elmes, A.; Ferreira, A.; Bento-Gonçalves, A.; Shakesby, R.; Ternan, J. e Williams, A. (1998) "Rainfall simulation plot experiments as a tool in overland flow and soil erosion assessment, NorthCentral Portugal”. Geookodynamik, Band XIX, 3-4, Bensheim, pp. 139-152. 